\title{
Hackathons, entrepreneurial life and the making of smart cities
}

\author{
Sung-Yueh Perng ${ }^{\mathrm{a}, *}$, Rob Kitchin ${ }^{\mathrm{b}}$, Darach Mac Donncha ${ }^{\mathrm{b}}$ \\ a Department of Sociology, Tunghai University, 1727 Sec.4, Taiwan Boulevard, Xitun District, Taichung 40704, Taiwan \\ ${ }^{\mathrm{b}}$ Maynooth University Social Sciences Institute and Department of Geography, National University of Ireland Maynooth, Maynooth, Ireland
}

A R T I C L E IN F O

\section{Keywords:}

Entrepreneurship

Spatiotemporal practices

Hackathon

Imitation

Passion

Smart city

\begin{abstract}
A B S T R A C T
Hackathons - quick prototyping events to create technical innovations for perceived challenges - have become an important means to foster innovation, entrepreneurship and the start-up economy in smart cities. Typically such events are organized by companies working in partnership with city administrations, and are predominately attended by technically literate participants who work in the tech sector. In this paper, we consider and critique the rationalities and practices of commercially-oriented hackathons. Drawing on Gabriel Tarde and recent re-engagement of his ideas, we analyse the spatiotemporal practices that modulate the passion and imitation in and around hackathons. We document how hackathon schedules and spaces are arranged in ways to extend but also exploit participants' passions for digital innovation and entrepreneurship, act as sites of upskilling and career progression, but also reproduce neoliberal and entrepreneurial labour and urban development. We argue that hackathons interpellate by attracting participants to desire and believe in entrepreneurial life and technocratic rationality to the effect of furthering the precarity of work and life and intensifying the corporatisation of cities. As such, hackathons reinforce the neoliberal underpinnings and ethos of entrepreneurial and smart urbanism.
\end{abstract}

\section{Introduction}

The first hackathon was held in 1999 as an invitation-only event for programmers with proven skills to gather and write software code to improve Internet security (OpenBSD, n.d.). They are now organised regularly as 'tech events' to foster innovation, entrepreneurship and social enterprise. Hackathons usually span a weekend and consist of coders, makers, domain experts, entrepreneurs and other interested parties working together to produce prototype solutions to a set of 'challenges'. At the end of the event, a judging panel announces the winning prototypes based on how well they addressed the proposed challenge, and in the case of commercially-orientated hackathons, their potential to be launched as a marketable product. The themes of hackathons are diverse, including those designed to address urban, technological or industry challenges, and the events can take place in a single city, multiple locations or simultaneously across the globe.

Just as there is variation in themes, there are many types of hackathons, including 'civic hackathons' such as Random Hack of Kindness and the National Day of Civic Hacking, organised to respond to social and community issues (Gregg, 2015; Irani, 2015). These civicminded hackathons have distinctive rationalities and practices and we discuss them elsewhere to consider the possibilities of 'shared technology making' (Perng, 2018). Here, we are concerned with hackathons themed around smart cities and technologies, and sponsored by large multinational IT corporations (such as IBM or Intel), start-up companies, and municipalities or government agencies, with a remit of improving urban services and economic growth. In the smart city context, hackathons are seen as a key pathway to foster entrepreneurship and innovation. They contribute to the 'smart economy' by providing a means of translating 'knowledge, skills and creativity of people ... into valuable processes, products and services' (Government of Ireland, 2008, p. 7). Being selected as the winner in such hackathons can be rewarded with a cash prize and/or team enrolment into incubator and accelerator programmes. The latter provides access to business networks, venture capital or investment by multinational corporations that maybe otherwise inaccessible. Accordingly, the social and economic capital to be gained at these events energise the participation of those with entrepreneurial ambitions and plans.

Inherent in the rationale for smart city hackathons is the belief that urban issues are solvable through technological fixes, with hackathons leveraging the innovation capacity of a crowd of talented, technically literate citizens to practice what Morozov (2013) terms 'solutionism'. Moreover, it is expected that the solutions produced will be commercialised and scaled up into marketable products and implemented through the sale/licensing to, or public-private partnerships (PPPs) with, city administrations. The ethos of market-based solutions to

\footnotetext{
* Corresponding author.

E-mail addresses: syperng@thu.edu.tw (S.-Y. Perng), Rob.Kitchin@mu.ie (R. Kitchin), darach.macdonncha.2014@mu.ie (D. Mac Donncha).
} 
public issues contributes to an on-going trend for city institutions to work with private industry through the contracting out or privatising services, and intensifies the ongoing neoliberalisation of urban governance (Kitchin, 2015; Marvin et al., 2016; Vanolo, 2013). Smart city hackathons contribute then to the transition from managerial to entrepreneurial urban governance by demonstrating how technological innovations can improve the delivery of public services and how markets can respond to emergent conditions and sustain such service provision and urban development (a transition also facilitated by other smart city initiatives, including living labs, urban testbeds, and innovation or smart districts; see Datta, 2015; Evans and Karvonen, 2014; Heaphy and Pétercsák, 2018; Hollands, 2008; Shelton et al., 2015).

Reflecting on this ongoing transition, existing debates on the entrepreneurial development of cities primarily centre on the variations of 'statecraft' that facilitate such a shift (Lauermann, 2018). Entrepreneurial city governments can pursue 'a direct, interventionist role' in the formulation of social, spatial and economic policies, amidst the 'recognition of the limits of privatism in the development and delivery of public policy' (Raco, 2012, p. 163). Urban laboratories, as embodiment of public-private partnerships, tech-led innovation and urban development, become another strategy that entrepreneurial city advocates adopt to create the city's economic, social and environmental future (Coletta et al., 2018; Karvonen and van Heur, 2014). Also, civil society groups can join local governments and international institutions (e.g., consultancy organisations) to mobilise and shape policies for 'coproduced entrepreneurialism' (McFarlane, 2012). In integrating smart city initiatives into municipalities and existing structures of local governance, partnerships that cut across public, private and civic domains are established and connect local and extra-territorial networks of key actors, technologies and organisations for promoting the technological acumen in the cities' economies and citizenship (Evans and Karvonen, 2014; Shelton et al., 2015).

Similarly, policies are mobilised to establish and integrate 'smart' economic and social programmes, and are also replicated elsewhere through the promotion and business agenda of a broad 'advocacy coalition' (Sabatier and Jenkins-Smith, 1993) of lobby and business groups (e.g., Smart City Council, TM Forum), governmental (e.g., the EU's European Innovation Partnership in Smart Cities and Communities) and non-governmental (e.g., Eurocities, Covenant of Mayors) stakeholders, and academics (e.g., smart city research institutes), or through municipalities replicating the initiatives of other competing cities and urban regions (Datta, 2015; Kitchin et al., 2017; Wiig, 2015). As such, the strategies developed in one urban context can circulate and become implicated in the interconnected trajectories of socio-spatial change' in different urban districts (Hart in Ward, 2006, p. 56), forming complex patterns of concurrent competition and cooperation among smart cities. Accordingly, these moorings and strategies for the development of smart cities can be understood as the latest incarnation of the entrepreneurial city (in much the same way as the creative city was a form of entrepreneurial urbanism).

However, the emergence of entrepreneurial cities and smart urbanism would not be possible without the participation of individuals, government agencies and private organisations; nor without the demonstrable progress of entrepreneurial pursuits and their ideas at hackathons. Therefore, what is missing in the current literature is a critical examination of the entrepreneurial activities that sustains smart economy and urbanism. In this paper, we draw on recent extensions to a Tardean approach that focuses on passion and imitation to examine entrepreneurial life in practice, with a specific focus on the logics, practices and work of hackathons. Our analysis foregrounds spatiotemporal practices and complex rationalities in Tarde's work to consider entrepreneurial urban activity that is insufficiently developed in the institutionalist approach to capitalist, neoliberal and exploitative operations that re-structure work, life and cities.

Following Tarde, we do not seek to examine societal or historic metamorphoses 'from afar, roughly, and from the outside', although recognising their lingering effects, and instead venture 'up close, in small numbers, and from the inside' (Latour and Lépinay, 2009, p. 28; original emphasis). We thus approach smart cities and their neoliberal logic not as a 'fundamental continuity in historic metamorphoses' (Tarde, 1903, p. 2), but rather by attending to spatiotemporal practices that are continuous, inventive and imitative in achieving their effects of sustaining and renewing particular desires, beliefs and ideas about such cities.

Our analysis draws on a case study of hackathons in Dublin conducted during 2014-5. Dublin was the focus of the study because the city was undergoing transition towards a smart city during this period (Coletta et al., 2018). At the municipal level, city administrations were preparing and formalising the city-region initiative 'Smart Dublin' to coordinate smart city initiatives across the four local authorities. Hackathons were regularly organised, with explicit smart city themes or featuring 'smart' technologies, e.g. dashboards, Internet-of-Things (IoTs), or other sensing technologies. These events were framed in public discourses and informal conversations as advancing personal careers, extending competitive edges for industries, building city and national economies, and creating cities that are more liveable, sustainable, resilient and accessible.

The case study sought to capture the complex social, entrepreneurial, technological and urban developments at and around hackathons. The research was undertaken through 40 interviews on hackathon and civic hacking practices in Dublin and by attending six hackathons, four to observe their unfolding in practice over the full event, and a further two as event participants. One of the authors was on a winning hackathon team and participated in two subsequent team meetings with a city council to explore future potential development of their prototype. Our analysis focuses on 24 interviews with attendees of corporately sponsored hackathons, rather than more civically-minded events. The respondents were aged from $20 \mathrm{~s}$ to $40 \mathrm{~s}, 19$ male and 5 female, reflecting the highly gendered nature of the events. Most of the participants were programmers, and four of the interviews were with organisers (all male). Before we detail the findings from the case study material, we discuss the utility of adopting a Tardean approach for examining entrepreneurial life in practice.

\section{Passions, imitations, entrepreneurship and hackathons}

Creativity, innovation and urban transformation have largely been explained through the lens of institutionalist economic growth or the fostering of a creative and knowledge economy (David and Foray, 2002; Gibson and Klocker, 2005; Mansfield, 1968; Scott, 2006; Wyly, 2013). However, to develop an approach to examine such change 'up close, in small numbers, and from the inside', we explore the modulation of imitation and passion in entrepreneurial life drawing on a reworking of Gabriel Tarde's ideas (1903, 2007). Tarde (1843-1904) was a French sociologist, whose work cuts across Anthropology, Psychology and Geography to understand the social as 'relational and in process', involving more-than-human aggregates and always in-formation (Barry, 2016, p. 3; Ruppert, 2012). In recent years, his work has been expanded to provide an alternative account to rational and evolutionary economics as to how socioeconomic relations and innovations unfold in practice (Latour and Lépinay, 2009; Barry and Thrift, 2007).

In Tarde's view, new developments emerge through imitation fuelled by passions (Tarde, 1903). Imitation consists of processes of repetition and resemblance, wherein practices and products are inimical to existing, successful endeavours. However, this does not lead to convergence and monotony, but through variation and invention produces differentiation and innovation. Tarde attributes change neither to individual ingenuity, nor an epochal understanding wherein each historical change is defined by ruptures to internal consistency within specific periods. Instead, he focuses on continuous modification, identifying the logic and actors that produce imitation and propagate inventions or ideas. Accordingly, he contends that 'all inventions and 
discoveries are composed of prior imitations' and subsequent inventions are situated in an indefinite series of possibilities created or annihilated over time (Tarde, 1903: 45).

Recent developments of Tarde's work have seen Latour and Lépinay (2009) rethinking capitalism not as a purely quantitative calculating regime, but pointing to the passions that intensify and lengthen capitalist networks and reach. That is, capitalism and economic development are driven not by rational decision-making, but passionate interests: 'the hope of winning, the pride of life, and the thirst for power' (Tarde, 2007, p. 632). For thinking about cities, other passions can be added: the desire to improve quality of life, the satisfaction of solving an intractable problem, the aspiration of creating a more efficient, safer, sustainable city, and so on.

An important development of a Tardean approach focuses on the relations between spatiotemporal practices and imitative effects, which Tarde considers, but does not fully engage with in his own work. For example, he pays attention to how imitation's 'influence is exerted not only over a great distance, but over great intervals of time' (Tarde, 1903, p. 35). Further developments from his work have sought to conceptualise social change in ontogenetic terms, in the sense of understanding passions and imitations as comprising complex rationalities, subjectivities and practices that can be leveraged for the remaking of times, spaces and socioeconomic relations (Borch, 2007; Thrift, 2004, 2008; Barry and Thrift, 2007; Karppi and Crawford, 2016). Thrift (2008) has discussed how knowledge-driven capitalism has become concerned with experimenting and creating spatiotemporal configurations that produce inventions and imitations. This 'worlding' involves the engineering of spaces and times, at varying scales and spans, to encourage wider replication and modification of social, economic and calculative undertakings to further corporate productivity or profitability. With respect to smart cities, what has been termed 'testbed' (Halpern et al., 2014) or 'experimental' (Evans et al., 2016) urbanism, wherein companies are enabled to prototype and trial new technologies in real-world settings - to create 'living labs' at the urban district scale is one form of such worlding.

Drawing on these ideas, we contend that an understanding of entrepreneurship and smart urbanism requires an approach that examines the spatiotemporal practices of passionate imitations. To date, geographic studies have been concerned with how entrepreneurship is shaped in diverse sectors, places or local economies, and sometimes further considers its implications on global cities (Cheshire and Woods, 2013; Chien, 2013; Golubchikov, 2010; Ortiz-Miranda et al, 2010). Recent work has started to pay attention to how entrepreneurship develops from 'enthusiast-driven innovation' (Brinks and Ibert, 2015) and the spatial and gendered practices of mothers to develop entrepreneurship, or 'mumpreneurship' (Ekinsmyth, 2011). A Tardean approach we suggest, would further sensitise analyses of 'temporary aggregates, partial stabilizations, [and] nodes in networks' (Latour and Lépinay, 2009, p. 9) that energise, propagate and capitalise on the complex rationalities for pursing entrepreneurial life within and beyond conventional spatiotemporal settings of innovation, such as the workplace (also Barry, 2013).
One such setting is hackathons, which seek to capitalise on the passions of their competitors to address urban issues by creating new products. Indeed, smart city hackathons typically target the passionate interest and entrepreneurial life of professionals working in software development, technology design, and innovation to encourage participation. These passions might relate to responding to a particular issue, the prospect of professional growth, or developing a new product that might seed a start-up company. For sponsors, the hackathon is not simply an altruistic endeavour; the event works to help fulfil their passion for fostering innovation, promoting a start-up economy, addressing an issue, or further an agenda, such as the neoliberisation of city services. However, contrary to the aspirations of participants, the short-term nature and power dynamics of hackathons most often reproduce precarious labour. Here, a process of interpellation and modulation offsets concerns over precarity and exploitation through the appropriation of ideas and labour. Indeed, hackathons seduce and interpellate by enticing participants 'to subscribe to and desire [their] logic and to willingly and voluntarily participate in [their] ideology and practice' (Kitchin and Dodge, 2011, p. 155) through appealing to their sense of altruism and offering rewards (e.g., opportunities, networks, friendship, prizes). Such desire fuels the invention and imitation of strategies to win events, resulting in competition between participants to the effect of intensifying the corporatisation of cities. We explore these issues in the following three sections, the first focusing on passion and professional life, the second examining the practices of imitation and invention, and the third detailing the spatiotemporal dynamics of events.

\section{Passions and professions}

Hackathons are spatiotemporal configurations of passions and professions. The events are organised in ways that only participants with desirable skills, usually at professional levels, are featured in the event programme and allowed in the space of competition. Hackathons typically start on a Friday evening and end on a Sunday evening. There are often no set hours, with teams working late at night on Friday and Saturday evenings, resuming early on Saturday and Sunday mornings. A typical schedule for a hackathon is summarised in Table 1. Within $48 \mathrm{~h}$, participants are expected to develop a project idea, sometimes from scratch, map out its design and functions, build a prototype app or machine, identify its technological and market niche, present the economic values of the project succinctly, and learn to work with team mates that they might not have known previously.

Accordingly, the skills that are present at a hackathon, along with the availability to attend over a full weekend, have immediate impact on team formation and its dynamics. Fig. 1 illustrates typical preferred skills for a hackathon. In addition to those with technical and marketing capabilities, participants with business and industry knowledge are valued. These insights and skills are valued because they facilitate initial project propositions and also shape the adjustment of project ideas throughout the weekend. They are useful for continuously explicating new markets and customers for prototypes and also presenting to and

Table 1

Typical hackathon schedule.

\begin{tabular}{|c|c|c|c|}
\hline & Friday & Saturday & Sunday \\
\hline Morning & $\begin{array}{l}\text { - Registered participants preparing project ideas } \\
\text { (not mandatory) }\end{array}$ & $\begin{array}{l}\text { - Start working on project: clarifying ideas and } \\
\text { specifying technical requirements }\end{array}$ & $\begin{array}{l}\text { Might have the final round of mentors or } \\
\text { workshops (e.g. for presentation) }\end{array}$ \\
\hline Afternoon & $\begin{array}{l}\text { - Participants starting to arrive and register for } \\
\text { the event around } 4-5 \mathrm{pm}\end{array}$ & $\begin{array}{l}\text { - Organizers introducing technical workshops and } \\
\text { mentors available for advice }\end{array}$ & $\begin{array}{l}\text { - Project development ends around } 3-5 \mathrm{pm} \\
\text { - Teams preparing for project presentation }\end{array}$ \\
\hline Evening & $\begin{array}{l}\text { - Introducing event sponsors } \\
\text { - Participants pitching ideas } \\
\text { - Forming teams and getting to know team } \\
\text { members } \\
\text { - Task allocation }\end{array}$ & $\begin{array}{l}\text { - Continue with project development } \\
\text { - Working late, with some events running on a } 24 \mathrm{~h} \\
\text { basis }\end{array}$ & $\begin{array}{l}\text { - Project presentation and result judging } \\
\text { - Networking throughout and after the event }\end{array}$ \\
\hline
\end{tabular}


Ticket Information

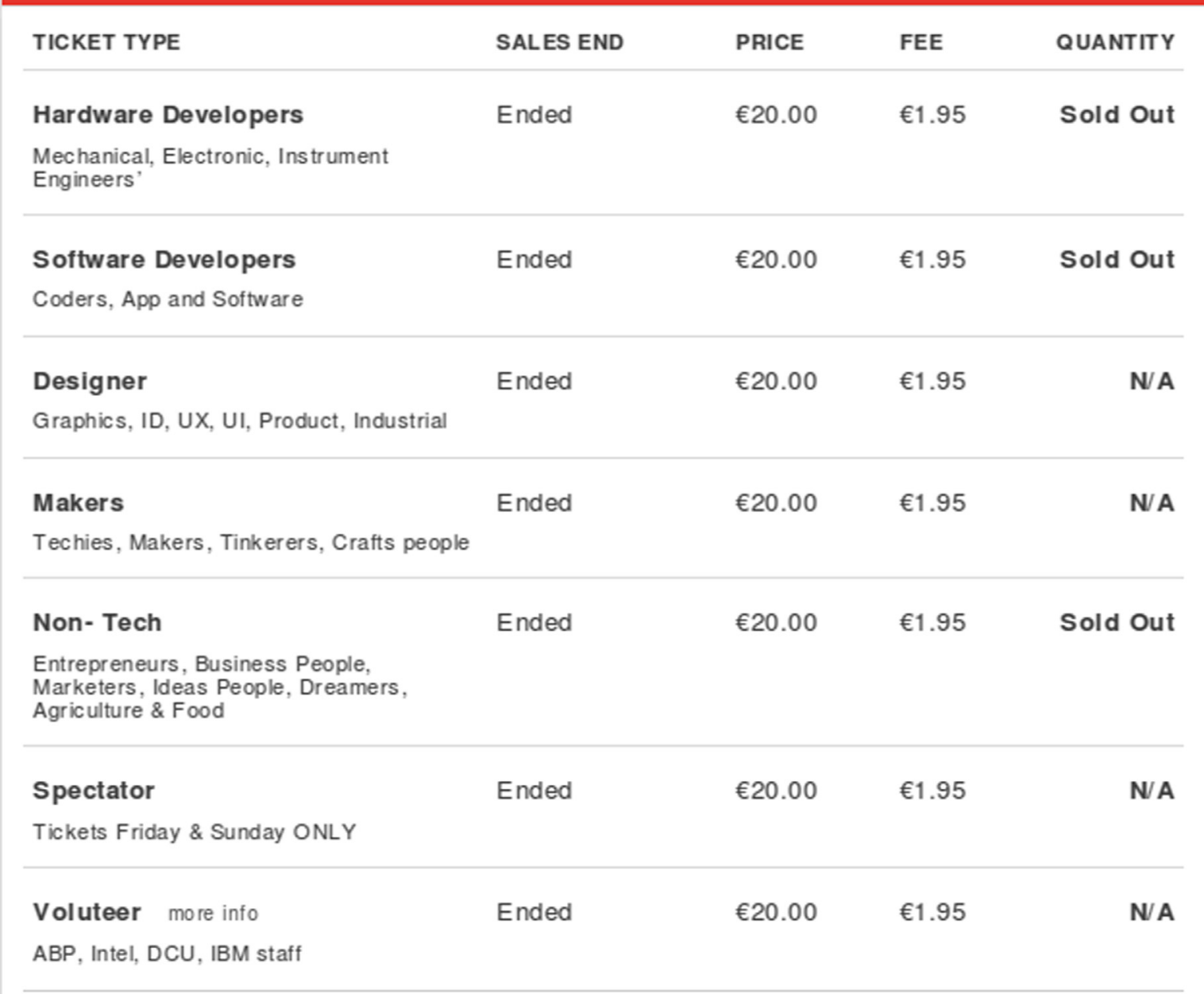

Fig. 1. Preferable hackathon skill sets and indicative costs for entering a hackathon. Source: Beefhack, https://www.eventbrite.co.uk/e/beefhack-tickets-15909838756\#.

answering questions from the judging panel.

However, participants who are not considered technically 'competent' or do not have the experiences and skills that are immediately perceivable by other people on the same team are largely ignored. Even for hackathon organisers, domain experts or interested citizens often fall outside their social imagination of participants. They are classified as 'Spectators' and their presence is limited to 'Friday \& Sunday ONLY' and the space where prototypes are developed can be a restricted area for them in fear that they would distract project development.

This exclusiveness is perhaps no surprise given that hackathons are often organised as a corporate 'open innovation' strategy (Ettlinger, 2017) to leverage the long-running passion for technology tinkering by 'makers', 'hackers' or 'expert amateurs' (Delgado, 2013; Kuznetsov and Paulos, 2010; Toombs et al., 2014). Hackathons provide ephemeral but recurrent places for these 'tinkers' or 'hackers' to share their passion and excitement together. Interviewee H33 'just want[ed] to have fun' by attending events, and participation for Interviewee H30 was 'just to come along and build ... things, anything software related, so just to hack for a weekend'. In pursuing their passions, a sense of 'hackathon community' grows among participants who 'don't have a specific interest in anything, except tech and maybe winning something' (Interviewee SCH39).

Hackathons become a communal space for these participants because 'it is very hard to get in contact with people who are similar minded, who have the technical skills to go along with my business background' (Interviewee H22). Once they are at the events, the participants become engrossed in the social and convivial atmosphere, as the interviewee noted:

It is self-motivated, but once you are there it is less like having to make yourself sit down and do it, it is a bit of fun. It is kind of a community thing as well.

Interviewee $\mathrm{H} 3$

In addition, hackathons provide a 'chance to work with friends' for Interviewee $\mathrm{H} 3$ and they participated in the same project to 'really work together'. The opportunity to refresh their shared passion in creating technologies gives hackathons their distinctive attractiveness that does not exist in other tech events, such as attending 'meetups' for talks. Accordingly, while passion for technology tinkering or creation might be a personal interest, hackathons provide a place where individual, social and affective rationalities are intertwined, which in turn intensifies the passion for hackathon participation.

Instrumental and affective rationalities mutually reinforce one another in shaping entrepreneurial life in smart cities. Tarde's (2007, p. 631) observation that 'passion and reason, from age to age, progress hand in hand' finds its resonance in the way entrepreneurial life is conducted by taking into account the passions for hackathon and the instrumental calculation concerning professional and entrepreneurial prospects. Technology development is often part of hackathon participants' everyday job and also a hobby. Knowledge and experiences 
acquired at work give them greater access to these events and in turn hackathons provide them with an opportunity to feed their passion by chasing the thrill in innovation competition:

... technology is something I have been extremely interested in. I have often hacked with Raspberry Pi's, Arduino, and I have done a lot of hardware hacking. My background is in information systems, so it kind of came together. And I thought great, if I can get with a group of guys who will put some thinking together and give 48 hours to creating something amazing, let's do it. So it was very much, just I love tinkering around and wanted to create something.

Interviewee $\mathrm{H} 2$

Despite hackathons being a place for passion and conviviality, participation requires other work to be performed immediately, including developing new project ideas, technical skills and participation strategies. However, the opportunities of employment and entrepreneurship remain promissory (see also Irani, 2015). This temporal slippage provides another means for hackathon organisers and sponsoring companies to capitalise on the passions of participants who are already subjected to exploitative work practices prevalent in the tech industry.

Hackathons paint promising futures for sponsoring companies, hosting cities and participating individuals. Participants are often promised the opportunity to stay in touch with ongoing innovations and future industry trends. Accordingly, for Interviewee H31, attending the events is a way of anticipating 'how banking will work in 2020, so what new systems, new services, new technologies we can introduce to make it better for customers and for the bank as well'. From the perspective of hackathon organisers and sponsors, these events provide a wealth of potential free ideas and investment opportunities to the organisers and sponsors. As noted by Interviewee H37 who organises hackathons as part of his job, the companies and municipalities involved in sponsoring or co-hosting hackathons can 'look at the ideas and say that is very, very interesting, I didn't actually see that happening'. Alternatively, the event can be a 'recruitment drive' for multinational or start-up companies to look for new talent by observing how they perform under stress and work with others in a real team. As far as indigenous or niche markets are concerned, hosting hackathons 'is a listening tool[, ...] listening to what people want moving forward regarding innovation, developing new products' and 'what the market is telling us'. The cumulative effect of the 'passion and reason' for organising and sponsoring hackathons is a boosterism for local economic development and the branding of Dublin as a hub of innovation on a global stage (Boyle, 1997):

... we have had participants from Sweden and Denmark, some of the Scandinavian countries, and Scotland and Italy ... Having 250 people attending a hackathon the same weekend when there are two other hackathons happening just shows that Dublin is a location for innovation.

Interviewee H37

Following Gregg (2015) and Ettlinger (2017), these are exploitative practices that appropriate the knowledge and labour of participants with little to no resistance. This is in large part due to the present and persistent alienation of subjectivity and passions at work. Particularly for programmers, because of the precariousness already in the industry (Kerr, 2017), they often develop 'pet projects' outside of work to keep up with new technologies, upgrade their skills, and reaffirm their creative subjectivities. The insecurity and precarity of work in the tech industry thus incentivise hackathon participation to the effect of furthering the exploitation of passionate tech labour. Accordingly, through hackathons, the practices of modulation become intensified, transforming the passions of individuals and their everyday activities into competition that is not very different from their everyday invasive and exhaustive work practices. Furthermore, such modulation ensures that upskilling occurs in the employees' own time, at their own costs, and consuming their own passions. For Interviewee H20, upskilling is important because, as an information system administrator, he undertakes very little code writing in his current job and hopes for future employment that has a greater element of coding.

So that was my idea, if I go along to this [hackathon] I will actually spend that amount of time [programming].

Interviewee $\mathrm{H} 20$

The division of labour in the IT and related industries means that, despite 'working with computers', there is 'a world difference' from software development, where his passion really lies, and how he wants to develop his career:

Well [as] sys[tem] admin, I go in, I download Java and I configure it to be installed on 80 computers. There is a small amount of development work in sys admin but it is very small, ... you might have to write 10 lines of code. ... I would say a single digit percent of my time is spent coding. I work in schools with teachers, so I might go in and the teacher would be like, I don't know how to burn a CD. So, it is not altogether technology enough. So, I might go in and teach teachers how to do things, whereas development is code all the way.

Interviewee $\mathrm{H} 20$

In addition, hackathons are appropriated for enhancing employment prospects because programmers cannot show the code they write or software they develop in their present employment to prospective future employers due to the commercial sensitivity of the projects. Faced with these constraints, they utilise hackathons as another means to demonstrate their technical competences:

... it is quite good to get extracurricular work, extracurricular code that you have worked on, like outside of my day to day job because I can't really show that code to anybody if I wanted to move on in the future or get a job or anything. ... So it is a nice way to actually go and do it and [show] you have done it.

Interviewee $\mathrm{H} 2$

The plentiful opportunities to make contacts and grow networks that would otherwise be difficult to achieve outside of hackathons are an important consideration for a participant whose plan is to become 'a tech entrepreneur as such' (Interviewee SCH39). Interviewee H22 took part in a banking hackathon because it presented him with the rare opportunity of pitching his business ideas to directly to the bank:

I ... would be around start-up events quite a bit. I love attending them. I had an idea to pitch and the fact that [bank name] was hosting it was an opportunity to talk to the bank, because sometimes it is hard to get meetings within the bank if you do have an idea that relates to them. So, they are really my motivations for going.

Interviewee $\mathrm{H} 22$

Similarly, Interviewee H21, noted that hackathons are another mechanism 'to improve my networking and see if I get an opportunity to join another company'. For this particular participant, the strategy paid off: 'because one week ago I wasn't working and I started working four or five days ago'.

Despite the passionate participation in hackathons, in our observations of winning teams, the prospect of any innovation and development beyond prototype stage is hampered most significantly by finding time to secure seed funding beyond cash prizes. Although hackathon organisers can partner with accelerators programmes, places in these programmes are not guaranteed and winning teams might still have to wait for a decision or undergo another round of competition for a place. Ironically, existing work commitments also get in the way of the winning team's project development after hackathons, as these commitments are often cited as reasons for absence from virtual or in-person meetings, if they are arranged at all. The passions observed at hackathons thus dwindle post-event as the prospect of securing funding and revising business plans diminishes. Accordingly, throughout the various 
stages of hackathons entrepreneurial life remain promissory. Yet participants are still driven by such promises and their own passions, strengthening the logic of competition and validating hackathon values.

\section{Inventions and imitations}

How entrepreneurial life is conducted and how the consequences unfold can be further unpacked by exploring the inventions and imitations of the competitive practices for winning hackathons. These practices are critical for participants to adapt to a fast-paced, intense but ambiguous innovation process and uncertain collaboration relationships. These practices are often learned and adapted in situ as the event unfolds, and failure to find a productive set of working relations and practices severely limits project development.

These inventions and imitations are necessary because there are considerable uncertainty and contingency inherent in the process of team formation and successful completion of prototypes. As Turner (2016) points out, prototypes are working solutions that are incomplete and are continuously being re-developed through partnership dynamics, tinkering and testing. A prototype as a project outcome depends on the right combination of interpersonal skills and technical competences, which is not always guaranteed. A fast pace is required by participating teams to recruit enough people (e.g. 5-6 team members), patch up enough skill sets to cover all aspects of project development (e.g. front and back-end developments, graphics, etc.), and form leadership to navigate the team through the troubles during prototype development. Most of the teams will not have been pre-formed and there is no formal management structure that can be readily applied to hackathons. As a result, hackathon teams have to come up with effective collaboration practices in situ, among a group of unfamiliar members, and without clear rules for leadership.

The contingency in team formation can significantly and unfavourably affect teams that start slower than others. It is not unusual that these teams will face situations where they are short of people or skill sets for the prototype they plan to build. Therefore, observing team formation as a hackathon organiser, Interviewee H37 commented that the 'negotiation that goes on behind the scenes' becomes a test of participants' abilities to 'react to different things and trying to swipe people from other teams', or retain their members when poached by other teams. Alternatively, if a team is formed, but lacks the leadership required to turn an idea into a project, 'the whole idea falls apart' and project members 'will jump ship to other teams'. Furthermore, after the swiping and negotiation, even if there are enough technical skills left to finish a prototype to a degree suitable for final presentation, the effective delivery of prototype ideas require other non-tech skills and experiences that might have become missing in the process.

However, developing hackathon techniques can be difficult and work practices cannot be readily replicated. Hackathons, as some participants observed, 'are all different' (Interviewee H33) and the differences can be due to hackathons having their own themes and attracting different kinds of participants. Also, participants can have their own attitudes, habits or skills, as well as having diverse expectations towards any given hackathon. Participants thus have to invent techniques in the face of such uncertainty and adversity. For some participants, whether 'you have a good idea ... is what matters' for ensuring successful hackathon results (Interviewee H21). They observed that a more polished idea can draw more attention during the initial idea pitch and can encourage more participants to join a team, which also widens technical capabilities for building the prototype. But the project idea does not have to be fully developed, leaving scope for team members to expand or make adjustments and also growing their stake to see through prototype development. To pursue the tactics further, some other participants either learn to discern which ideas and teams to join, or organise a team themselves before a hackathon starts:

Some people get there, they already have a team so they don't get there alone. ... [I]t is much easier because probably they have been working on the idea before. ... They maybe brainstorm before, so it would be easier to move on with the idea and build the project.

Interviewee $\mathrm{H} 21$

The tweaking of participation techniques does not stop at the end of a hackathon. Instead, the techniques are continuously reconfigured by drawing upon the reflection on the current one and setting out adjustments for subsequent events. For example, Interviewee H23 emphasises actions rather than discussions and a more realistic goal for project development after an unsuccessful experience. The reorientation of hackathon strategies would focus on consolidating the team's efforts by considering what is 'achievable during the weekend', which is likely 'to be something much smaller' so that the team can 'reduce the amount of discussion on what this thing could be and shrink it down'. The reflection, preparation and revision for hackathon participation are 'imitative techniques' that individual participants devise or acquire to increase the chance of winning, which compels more participants to follow suit to stay competitive in the events.

The importance of these imitative techniques grows as participants take their participation more seriously, treating it as a weekend profession and calculating their 'return on investment'. Many hackathons ask for entry fees and there are potentially other costs, including accommodation for a weekend, travel and other expenses, which in turn adds to the intensifying determination for better results:

... if I was going to Edinburgh I would need to ensure that I have a team before the hackathon ... . My mindset would be more about competition and winning. That is the main difference. ... [Otherwise,] you can just be relaxed and have fun. But if you need to make an investment you expect a return on the investment.

Interviewee $\mathrm{H} 31$

Crafting these techniques takes an emotional toll on participants and affect the emotional charge and participation strategies in individual teams and across the events. For example, Interviewee H2O 'started off lackadaisical and then kind of got into the flow of things', but was stunned by the intensity and devotion to prototyping. The level of competition that can accumulate at a hackathon took him by surprise: 'I was like, whoa, these guys spend a lot of money on this and really expect it to produce good stuff'. With this realisation, he has worked to improve his tactics for future events. He will 'pitch the idea and say, I need a business guy, a designer and I need an iOS guy, come and join me, we are going to win. I am going to be serious from the beginning'.

Consequently, the more invested participants are regarding hackathon participation, emotionally or investment-wise, the more likely they are to seek control over prototype development. As participants acquire more intimate and practical knowledge about how hackathons are organised and how teams work (or fail), they leverage their participation experiences and insights to plan subsequent events. For Interviewee H30, hackathon participation stimulated ideas about how he could improve his tactics for participating by imitating others'. He would become 'more vocal' and engage more actively once he acquired the knowledge about the mechanics of hackathons, particularly in terms of the development of ideas and projects:

But next time, because I know it is a bit of fun and everyone pitches ideas and they can be loose ideas, I might even take part in that. ... I would probably be a little bit more vocal and participating from the beginning. It took the first few hours to get comfortable with the environment but now that I know what to expect I would probably do a bit more.

In other words, as hackathon participation techniques mature and become imitated, the 'fun' element, which was an initial motivation for some participants, can diminish, replaced by a more 'controlled' approach to prototype development. Prior preparation has ceased to be a 
matter of competing on a level playing field for Interviewee H22, but instead is to get a head start. He would exact the project idea and relevant details for a greater chance to enter an incubator programme and launch a start-up business:

I will already have a team and I will be much more prepared. I will have the pitch ready and a draft outline of what I need to get done over the weekend. So, it will be a lot more controlled with an end purpose of hopefully getting incubation space because I have experience in the area and it could be a reality. That is the difference.

\section{Space, programme and progress}

Hackathon practices are shaped by the spatiotemporal dynamics of the events. These dynamics are far from neutral and are the result of building spatial (and knowledge) infrastructure, rearranging spatiotemporal relations, and engineering spaces for collaboration and modulation (Thrift, 2008). In this process, hackathon organisers also seek invention and imitation, but do so through the fine-tuning of the spatiotemporal configuration of hackathons, particularly in terms of event programmes and spaces for innovation. These practices are to ensure the teams progress well and provide a return on investment for the sponsoring companies. These arrangements do not specify direct and clearly defined outcomes. Instead, they engineer 'active spaces' as 'a means of harnessing and working with process in order to produce particular propensities' and intensify entrepreneurial governance practices (Thrift, 2008, p. 93; also Wiig and Wyly, 2016).

Some arrangements conform to event organisation conventions: hiring venues in central locations and with easy public transportation for increasing participant numbers. Simultaneously, tweaks and inventions are carried out for increasing hackathon productivity. Engineering spaces for the fluid and intersecting flows of participants and information at hackathons is one such example. Hackathons start as a big crowd, for introducing the events and sponsors, and also for participants to share ideas and get to know each other. They then disperse as small groups into different rooms or segments of space at the venue after teams are formed, engaging in conversation and working on their projects (see Fig. 2 for illustrations). At the same time, sponsors who provide equipments or have promotional stands have to be allocated with appropriate space for participants to reach them and seek advice when required. Before the small groups all re-congregate for the final stage of presenting project results and judging, there are intermittent workshops or mentor sessions where participants across the various projects gather to get feedback from workshop leaders or mentors.

As noted during an interview with a hackathon organiser, the material and spatial arrangements for the events focus on making 'the building work to the schedule' for bringing about participants' collective creativity, rather than asking them to adapt to the venue's constraints. Explaining in more detail, the organiser (Interviewee H37) went through different aspects they had considered during the development of a dedicated floor for hackathons:

where people enter, registration, where we serve the food, where would the main teams go to when they actually sit down when the teams are formed and get into developing the idea. ... And I suppose that is where we came out with the layout ... so it is a flow, if that makes sense, and it is the design with that flow in mind.

Creating the 'flow', the organiser and his team developed 'the idea of just stripping the floor out ... and just leaving it in that raw state with no carpets or whatever', for 'giving people that freedom to do what they need to do' during the events (see Fig. 3). There is also a slight twist to the flow in the space by intentionally having some space that is separated off from the main hackathon area, allowing participants to have productive breaks:

I think the format of having multiple different rooms where people could come and go and break out for chats with mentors, to take time out to go for a coffee, I think the agenda allows for the intense debate and working on ideas, but it also facilitates time out as well. Interviewee $\mathrm{H} 19$

At the same time, while curating the flow of creativity, 'you don't want people spread out all over the place', as Interviewee H37 commented on another aspect of arranging hackathon space. This has to be balanced with other considerations, such as: 'people don't feel they are breathing down each other's necks with the teams and people listening in and things like that'. Therefore, for example, the space available for a particular hackathon has to be adjusted according to participant numbers so that participants are 'in a tight enough area where there is a buzz created'. Other arrangements that have been experimented, and considered as successful, include furniture (e.g. adding couches and coffee tables as informal meeting area at a smaller hackathon), the placement of food areas or setting up a dedicated space for sponsors for their own activities, such as informal interviews. These design considerations and space configurations are a means of space engineering for harnessing creativity and producing a 'culture of innovation'.

The design of hackathon programmes is another important aspect of engineering the event to 'allow directed action to take place' for enhancing participant productivity. Programme tweaking practices here are not 'reductive, just because they limit action in particular planes. Instead, they must be seen as productive variations, allowing new things to come into the world that add new kinds of weight and energy' (both quotes from Thrift, 2004, p. 875).

The tweaking of hackathon programmes to 'add new kinds of weight and energy' to increase innovation and productivity is also a continuous process. As Interviewee H37 commented, the tweaking 'doesn't stop, it never stops' and 'it is constantly evolving and experimenting'. While most hackathon schedules conform to the pattern outlined earlier, tweaks to the schedules are carried out according to the theme of a hackathon or where it is hosted. For a hackathon sponsored by an Irish
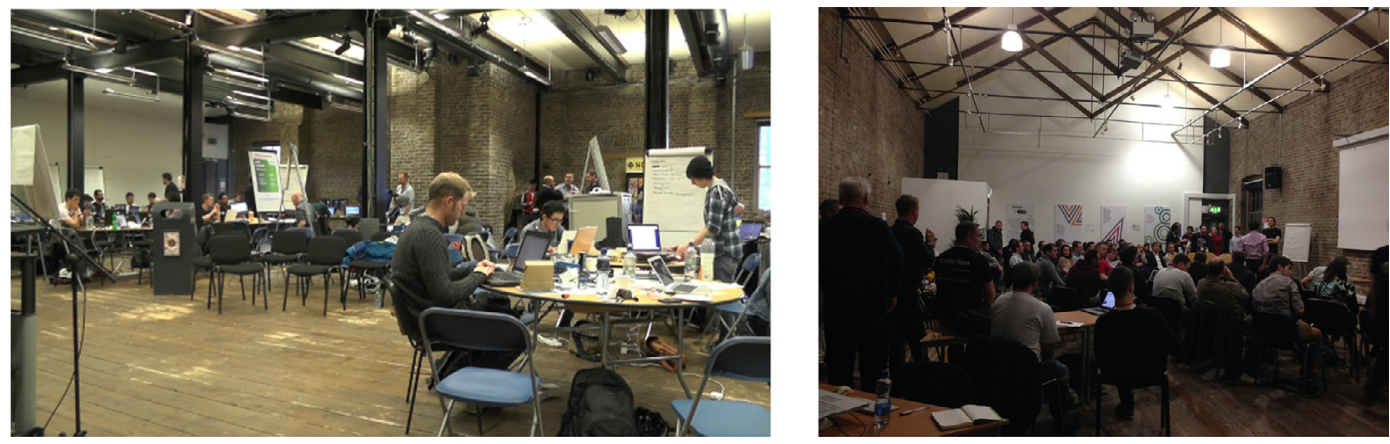

Fig. 2. Hackathon crowds dispersed into small groups for projects (left) and gathered for event opening and conclusion pitches (right). Source: authors. 

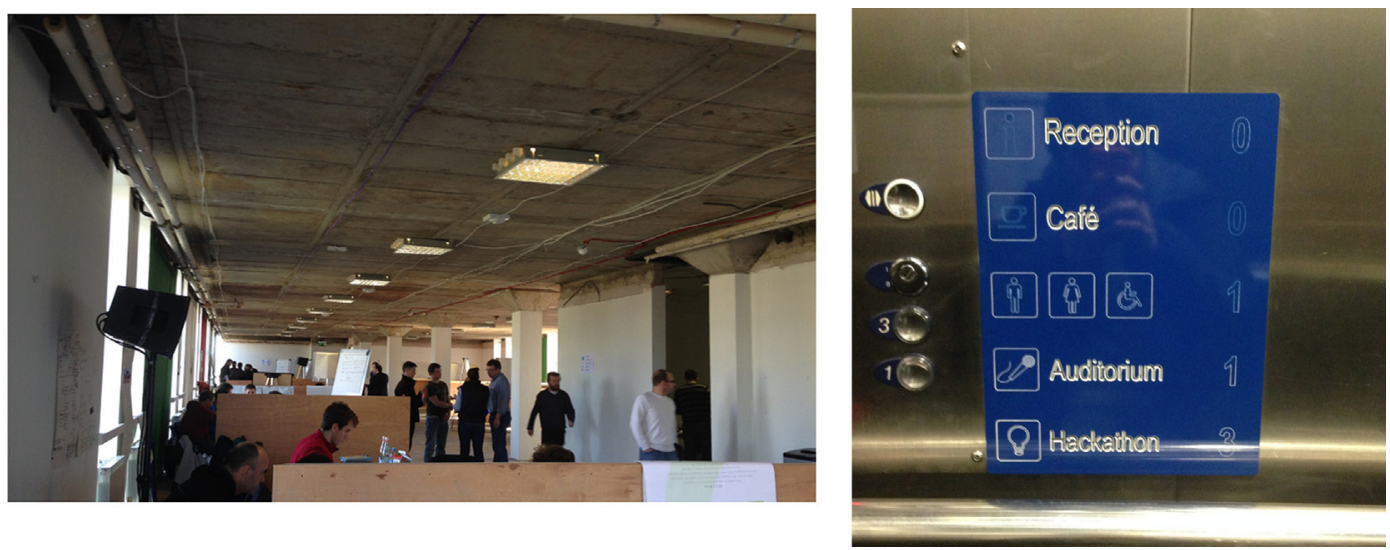

Fig. 3. Dedicated hackathon floor and space design.

Source: authors.

bank, the bank brought in a consultancy and financial technology company to help run it. The bank took on board the programme format suggested by the company because the people in the company 'have been through a number of these, they know what works, they know what hasn't worked in the past' (Interviewee H19). But the bank made local adjustments for creating more opportunities of interaction during the event rather than simply focusing on coding:

if you look at the amount of time that is put aside for pure hacking, it is only about $50 \%$ of the agenda. ... the agenda allows for the intense debate and working on ideas but it also facilitates time out as well. ... If you moved from $50 \%$ coding to 70 or $80 \%$, I think people would just get bored and burn out.

Interviewee $\mathrm{H} 19$

Another critical part of hackathon programme tweaking is invested in ensuring progress and energising the events. Measures put in place to guarantee return on investment for sponsors are telling examples. For the sponsors, the immediate value of sponsoring the events does not rest solely on the prototypes and the teams behind them. The prototypes and teams both require further developments and subsequent funding for launching them as products is not always guaranteed. Instead, the purpose for sponsoring companies is to disperse their products or values into the events, to enculturate their participants, to harvest fresh ideas, and spot potential new talent. Technical workshops, for example, are opportunities to introduce participants to their new data analytics platforms, new hardware to build IoT devices, or new tools for accessing data from particular sources to create new services. Alternatively, for hardware manufacturers, they can have stands that are staffed throughout the weekend to provide friendly technical assistance. The stands provide support to participants and in turn gather valuable feedback for these companies to improve their products and manuals, which would otherwise require additional costs and efforts to obtain.

\section{Conclusion}

From passions for tinkering to uncertainty in prototyping, we have analysed the passionate participation and production of hackathons and entrepreneurial life in smart cities. Hackathon participants, organisers and sponsors use the events as opportunities to pursue their passions for digital innovations and creating new products. The practices of participating and organising hackathons are both inventive and imitative and seek to create more opportunities for producing better prototypes at the close of the events, individually for the teams and collectively for the hackathon organisers. Participation in hackathons raises the hopes of acquiring more skills, greater access to business networks, a sharper sense of potential innovation, and more knowledge about future markets. These are all necessary ingredients for better career trajectories, further development of prototypes, attracting investment to fund the development and ultimately establishing start-up companies. These practices therefore lengthen passions for digital innovation and also entrepreneurial life.

However, our analysis of the modulation of passion and imitation also illustrates that precarity, ambiguity and uncertainty already plaguing programmers and prototypes alike are engineered into the development of entrepreneurial life and smart urbanism. Hackathons capitalise on the work precarity of passionate tech labour for ensuring that upskilling becomes outsourced to individual participants without any guarantee of career advancement. The lifespan of prototypes is contingent upon the success at hackathons, which in turn relies on the fast formation of a team at the outset of the events with an appropriate skill set, collaborative ethos and leadership. Furthermore, the pressure to succeed compels participants to focus on developing participation techniques in between hackathons and to extend the control and management of prototyping processes during competition. Hackathon participation thus becomes a profession in its own right, demanding both material and immaterial investments in the forms of time, money, physical presence and continued preparation for, and improvement on, participation practices. The modulation of passions and imitations thus extends the exploitative practices at work into urban life and widens the corporatisation of urban development.

Leveraging Tarde and recent engagements with his work, we suggest a focus on the modulation of passion and imitation as an analytical lens for subsequent examination of urban everyday life, digital innovation and smart urbanism. We have demonstrated how the approach ventures into complex rationalities in everyday practices to pursue entrepreneurship but also remains sensitive towards to the interpellation of neoliberalising and exploitative practices at and around hackathons. Such an approach follows the processes whereby rationalities become diversified, intensified, affected and changed when coming into contact with one another. In our case study, we focused on the passions for innovations and the imitations of hackathon and entrepreneurial pursuits, examining how these diverse practices, whether exercised by individuals, government agencies or multinational corporations, have energised digital innovations and smart urbanism and furthered the neoliberalisation of cities. There are many other unfolding practices and initiatives that can be examined by following a Tardean approach to reveal the passionate but precarious futures of individuals, prototypes, proof-of-concepts, open innovation schemes, innovation districts, governance processes and government restructuring in the pursuit of smart urbanism. Such research can yield further insights into how the pursuits of digital, entrepreneurial and smart cities generate their own precarity, ambiguity and uncertainty while adopting open, transparent and collaborative logics and practices. 


\section{Funding details}

This work was supported by the European Research Council under Grant ERC-2012-AdG-323636-SOFTCITY.

\section{Acknowledgement}

The research for this paper was provided by a European Research Council Advanced Investigator Award, 'The Programmable City' (ERC2012-AdG-323636). We are grateful to Aphra Kerr, Robert Fletcher and the anonymous referees for feedback on earlier versions of the paper.

\section{References}

Barry, A., 2013. Material Politics: Disputes along the Pipeline. Wiley Blackwell, Oxford. Barry, A., Thrift, N., 2007. Gabriel Tarde: Imitation, invention and economy. Econ. Soc. 36 (4), 509-525.

Barry, A., 2016. The politics of contingency: Events, traveling models, and situations. In: Working Papers of the Priority Programme 1448 of the German Research Foundation, Adaptation and Creativity in Africa: technologies and significations in the making of order and disorder. Retrieved from http://www.spp1448.de/fileadmin/media/ galleries/SPP_Administration/Working_Paper_Series/SPP1448_WP19_Barry.pdf.

Brinks, V., Ibert, O., 2015. Mushrooming entrepreneurship: The dynamic geography of enthusiast-driven innovation. Geoforum 65, 363-373.

Borch, C., 2007. Crowds and economic life: Bringing an old figure back in. Econ. Soc. 36 (4), 549-573.

Boyle, M., 1997. Civic boosterism in the politics of local economic development: 'Institutional Positions' and 'Strategic Orientations' in the consumption of hallmark events. Environ. Plann. A 29 (11), 1975-1997.

Cheshire, L., Woods, M., 2013. Globally engaged farmers as transnational actors: Navigating the landscape of agri-food globalization. Geoforum 44, 232-242.

Chien, S.-S., 2013. New local state power through administrative restructuring - a case study of post-Mao China county-level urban entrepreneurialism in Kunshan. Geoforum 46, 103-112.

Coletta, C., Heaphy, L., Kitchin, R., 2018. From the accidental to articulated smart city: The creation and work of 'Smart Dublin'. Eur. Urban Reg. Stud. https://doi.org/10. $1177 / 0969776418785214$.

Datta, A., 2015. New urban utopias of postcolonial India: 'Entrepreneurial urbanization' in Dholera smart city, Gujarat. Dialogues Human Geogr. 5 (1), 3-22.

David, P.A., Foray, D., 2002. An introduction to the economy of the knowledge society. Int. Soc. Sci. J. 54 (171), 9-23.

Delgado, A., 2013. DIYbio: Making things and making futures. Futures 48, 65-73.

Ettlinger, N., 2017. Open innovation and its discontents. Geoforum 80, 61-71.

Ekinsmyth, C., 2011. Challenging the boundaries of entrepreneurship: The spatialities and practices of UK 'Mumpreneurs'. Geoforum 42 (1), 104-114.

Evans, J., Karvonen, A., 2014. 'Give me a laboratory and I will lower your carbon footprint!'-Urban laboratories and the governance of low-carbon futures. Int. J. Urban Reg. Res. 38 (2), 413-430.

Evans, J., Karvonen, A., Raven, R., 2016. The experimental city: New modes and prospects of urban transformation. In: Evans, J., Karvonen, A., Raven, R. (Eds.), The Experimental City. Routledge, London, pp. 1-12.

Gibson, C., Klocker, N., 2005. The 'cultural turn' in Australian regional economic development discourse: Neoliberalising creativity? Geograph. Res. 43 (1), 93-102.

Golubchikov, O., 2010. World-city-entrepreneurialism: Globalist imaginaries, neolibera geographies, and the production of new St Petersburg. Environ. Plann. A 42 (3), 626-643.

Government of Ireland, 2008. Building Ireland's Smart Economy: A Framework for Sustainable Economic Renewal. Department of the Taoiseach, Dublin.

Gregg, M., 2015. Hack for good: speculative labour, app development and the burden of austerity. Fibreculture J. 25, 185-202.

Halpern, O., LeCavalier, J., Calvillo, N., Pietsch, W., 2014. Test-bed urbanism. Public Cult. 25 (2), 273-306.

Heaphy, L., Pétercsák, R., 2018. Building smart city partnerships in the 'Silicon Docks'. In: Coletta, C., Evans, L., Heaphy, L., Kitchin, R. (Eds.), Creating Smart Cities. Routledge, London, pp. 76-89.
Hollands, R.G., 2008. Will the real smart city please stand up? City 12 (3), 303-320.

Irani, L., 2015. Hackathons and the making of entrepreneurial citizenship. Sci. Technol. Human Values 40 (5), 799-824.

Karppi, T., Crawford, K., 2016. Social media, financial algorithms and the hack crash. Theory, Cult. Soc. 33 (1), 73-92.

Karvonen, A., van Heur, B., 2014. Urban laboratories: Experiments in reworking cities. Int. J. Urban Reg. Res. 38 (2), 379-392.

Kerr, A., 2017. Global Games: Production in the Digital Game Industry. Routledge, NY.

Kitchin, R., 2015. Making sense of smart cities: Addressing present shortcomings. Cambridge J. Reg., Econ. Soc. 131-136.

Kitchin, R., Coletta, C., Evans, L., Heaphy, L., Mac Donncha, D., 2017. Smart cities, urban technocrats, epistemic communities, advocacy coalitions and the 'last mile' problem. it - Inform. Technol. 59 (6), 275-284.

Kitchin, R., Dodge, M., 2011. Code/Space: Software and Everyday Life. MIT Press, Cambridge, Mass.

Kuznetsov, S., Paulos, E., 2010. Rise of the expert amateur: DIY projects, communities, and cultures. In: Proceedings of the 6th Nordic Conference on Human-Computer Interaction: Extending Boundaries. ACM, NY, pp. 295-304.

Latour, B., Lépinay, V.A., 2009. The Science of Passionate Interests: An Introduction to Gabriel Tarde's Economic Anthropology. Prickly Paradigm Press, Chicago.

Lauermann, J., 2018. Municipal statecraft: Revisiting the geographies of the en trepreneurial city. Progr. Human Geogr. 42 (2), 205-224.

Mansfield, E., 1968. The Economics of Technological Change. Norton, NY.

Marvin, S., Luque-Ayala, A., McFarlane, C. (Eds.), 2016. Smart Urbanism: Utopian Vision or False Dawn. Routledge, NY.

McFarlane, C., 2012. The entrepreneurial slum: Civil society, mobility and the co-production of urban development. Urban Stud. 49 (13), 2795-2816.

Morozov, E., 2013. To Save Everything, Click Here: The Folly of Technological Solutionism. PublicAffairs, NY.

OpenBSD, n.d. 'Hackathons', OpenBSD, available from http://www.openbsd.org/ hackathons.html (accessed 19.03.15).

Ortiz-Miranda, D., Moreno-Perez, O.M., Moragues-Faus, A.M., 2010. Innovative strategies of agricultural cooperatives in the framework of the new rural development paradigms: The case of the Region of Valencia (Spain). Environ. Plann. A 42 (3), 661-677.

Perng, S.-Y., 2018. Shared technology making in neoliberal ruins: Rationalities, practices and possibilities of hackathons. The Programmable City Working Paper 38. Retrieved from https://osf.io/k793w.

Raco, M., 2012. A growth agenda without growth: English spatial policy, sustainable communities, and the death of the neo-liberal project? GeoJ. 77 (2), 153-165.

Ruppert, E., 2012. The governmental topologies of database devices. Theory, Cult. Soc. 29 (4-5), 116-136.

Sabatier, P., Jenkins-Smith, H.C. (Eds.), 1993. Policy Change and Learning: An Advocacy Coalition Approach. Westview Press, Boulder, CO.

Scott, A.J., 2006. Entrepreneurship, innovation and industrial development: Geography and the creative field revisited. Small Bus. Econ. 26 (1), 1-24.

Shelton, T., Zook, M., Wiig, A., 2015. The 'actually existing smart city'. Cambridge J. Reg., Econ. Soc. 8 (1), 13-25.

Tarde, G., 1903. The Laws of Imitation. HHolt and company, New York.

Tarde, G., 2007. Economic psychology. Econ. Soc. 36 (4), 614-643.

Thrift, N., 2004. Intensities of feeling: Towards a spatial politics of affect. Geografiska Annaler 86B (1), 57-78.

Thrift, N., 2008. Pass it on: Towards a political economy of propensity. Emotion, Space Soc. 1 (2), 83-96.

Toombs, A., Bardzell, S., Bardzell, J., 2014. Becoming makers: Hackerspace member habits, values, and identities. J. Peer Prod. 5.

Turner, F., 2016. Prototype. In: Peters, B. (Ed.), Digital Keywords: A Vocabulary of Information Society and Culture. Princeton University Press, Princeton, NJ, pp. $256-267$.

Vanolo, A., 2013. Smartmentality: The smart city as disciplinary strategy. Urban Stud. 51 (5), 883-898.

Ward, K., 2006. 'Policies in motion', urban management and state restructuring: The trans-local expansion of business improvement districts. Int. J. Urban Reg. Res. 30 (1), 54-75.

Wiig, A., 2015. IBM's smart city as techno-utopian policy mobility. City 19 (2-3), $258-273$.

Wiig, A., Wyly, E., 2016. Introduction: Thinking through the politics of the smart city. Urban Geogr. 37 (4), 485-493.

Wyly, E., 2013. The city of cognitive-cultural capitalism. City 17 (3), 387-394. 